\title{
O REGIME DE CICLOS DE APRENDIZAGEM E A HETEROGENEIDADE DE SEUS EFEITOS SOBRE A PROFICIÊNCIA DOS ALUNOS
}

\author{
SANDRo CARVALHO * \\ SERgio Firpo ${ }^{\dagger}$
}

\begin{abstract}
Resumo
Neste artigo avaliamos o impacto da adoção do regime de ciclos ao longo da distribuição intra-classe de proficiência em matemática e português. Investigamos crianças matriculadas nas $4^{\mathrm{a} e} 8^{\mathrm{a}}$ séries. Os resultados indicam que há fraca relação entre a mudança de um regime seriado para o de ciclos sobre o desempenho, mesmo ao longo da distribuição. Contudo, no sentido inverso, a readoção das séries gerou impactos positivos no desempenho de matemática na $4^{\mathrm{a}}$ série para todos os pontos da distribuição. Pode-se concluir que, em geral, a reprovação não parece gerar aumentos de esforço dos alunos, sobretudo entre alunos mais velhos.
\end{abstract}

Palavras-chave: Educação; Não retenção; Desempenho Acadêmico.

\begin{abstract}
We evaluate the impact of non-retention policies over the distribution of academic achievement of elementary Brazilian public schools students. Results suggest a weak correlation between the adoption of non-retention policies and the academic achievement. However, in the opposite direction, readopting grade repetition showed a positive impact on 4th grade math students over the entire distribution. In general, we may say that grade repetition does not seem to increase students' efforts, especially in older students.
\end{abstract}

Keywords: Education; Non Retention; Academic Achievement.

JEL classification: I20, I28, I29.

DOI: http://dx.doi.org/10.1590/1413-8050/ea374

\footnotetext{
* Técnico de planejamento e pesquisa do Instituto de Pesquisa Econômica Aplicada (IPEA). Email:sandro.carvalho@ipea.gov.br

† São Paulo School of Economics (FGV-EESP). E-mail: sergio.firpo@fgv.br
} 


\section{Introdução}

Há alguns fatores bem estabelecidos na literatura para explicar as altas taxas de evasão escolar durante o ensino fundamental encontradas em países em desenvolvimento. Entre eles, destacam-se quatro: (i) restrições de crédito/insuficiência de renda da família, as quais obrigam crianças desde muito cedo a trabalharem; (ii) dificuldade de acesso às escolas, quando as escolas disponíveis encontram-se ou muito distantes ou quando há vagas insuficientes; (iii) currículo escolar defasado e desinteressante; (iv) altas taxas de reprovação nos primeiros anos da etapa escolar.

Dentre esses fatores, as altas taxas de reprovação são consideradas as principais responsáveis pela baixa proporção de conclusão do ensino básico. ${ }^{1}$ No início dos anos 90, o continente latino americano apresentava as piores taxas de reprovação e evasão do mundo, e estas foram identificadas como o principal problema do sistema de educação básica da América Latina (Schiefelbein \& Wolff 1993). Apesar dos esforços recentes de inclusão das crianças na escola na maior parte do continente, (Filmer \& Pritchett 1999, Wolff et al. 2002) as taxas de evasão continuaram altas, principalmente entre famílias mais pobres. ${ }^{2}$

Uma iniciativa levada a cabo em algumas escolas e redes de ensino público no Brasil em meados dos anos 90 visava, dentre outros objetivos, à diminuição da evasão via eliminação da reprovação nos primeiros anos da vida escolar. Essas redes de ensino passaram a adotar o regime de ciclos de aprendizagem, por meio da progressão continuada entre anos de estudo. O mais usual foi que do primeiro ao último ano do ensino fundamental I (antigo primário, ou antigas $1^{\mathrm{a} a} 4^{\mathrm{a}}$ séries) virasse um único ciclo, cuja aprovação ou reprovação ocorreria apenas no último ano. Em torno de $10 \%$ das escolas do país passaram a adotar o regime de ciclos. Para uma boa apresentação da dimensão e extensão da política de ciclos, ver Franco (2004).

Uma primeira crítica à política dos ciclos é que a manutenção na escola não garante que o desempenho escolar da criança seja melhorado, e que o problema da evasão estaria sendo apenas adiado. Além disso, pode-se pensar que a adoção de ciclos possa ainda acarretar dois efeitos sobre o aprendizado das crianças que, mesmo sob o regime seriado, não iriam evadir das escolas.

O primeiro efeito sobre aprendizado é um efeito direto e sua magnitude depende da forma que a eliminação da retenção no sistema de ciclos é implantada. Roderick \& Engel (2001) afirmam que a teoria motivacional sugere que alunos serão estimulados a atingir uma meta se eles valorizarem o objetivo a ser buscado e acreditarem que esse objetivo possa ser alcançado. Por sua vez, o valor que os alunos atribuem aos objetivos pode ser intrínseco ou extrínseco. Ainda de acordo com as autoras, a motivação intrínseca acontece quando a tarefa a ser realizada é interessante e recompensadora em si mesma, ou quando seu resultado é considerado importante por causa de interesses

\footnotetext{
${ }^{1}$ Os críticos da retenção afirmam que ao prejudicar a autoestima dos repetentes, expor a criança aos mesmos materiais que ela já estudou, usualmente com o mesmo professor, e que por não atacar as razões fundamentais por trás do baixo desempenho cognitivo dos alunos, ela gera um forte desinteresse dos repetentes na educação formal, levando à evasão e à entrada precoce no mercado de trabalho. Para evidências sobre o aumento que a repetência causa na probabilidade de evasão, veja Jimerson et al. (2002), Allensworth (2005), Jacob \& Lefgren (2009), Manacorda (2012) e King et al. (2008). Para o Brasil, ver Ribeiro (1991).

${ }^{2}$ A reprovação escolar também está diretamente ligada à insuficiência de renda, isto é, crianças de famílias pobres, devido a causas como pais com baixa escolaridade e piores condições de moradia e nutrição, têm maior dificuldade na escola, o que leva a maiores taxas de reprovação.
} 
imediatos ou como meios para atingir metas futuras. Motivações extrínsecas ocorrem quando o objetivo a ser alcançado é perseguido devido à valorização social que acarreta ou para receber recompensas oferecidas e evitar punições.

A ameaça da retenção e a necessidade de atingir um padrão mínimo é claramente uma motivação extrínseca para alunos se esforçarem, e consequentemente alcançarem um bom desempenho acadêmico, que terá diferentes efeitos sobre diferentes estudantes. Alunos em condições muito aquém das requeridas para alcançarem um padrão mínimo podem inclusive ter seu desempenho prejudicado pela ameaça da reprovação se acreditarem que mesmo seus melhores esforços serão inúteis para evitar a punição. Por outro lado, a possibilidade de retenção não terá efeito algum em crianças que possuam um alto grau de motivação intrínseca, que, pode-se supor, sejam em geral os melhores alunos.

As propostas de ciclos buscam ir muito além da simples promoção automática, advogando mudanças complexas e profundas nas práticas pedagógicas. Averígua-se, entretanto, que a implantação dessas propostas ocorreu em condições bastante problemáticas levando a um certo esvaziamento dessas políticas (Mainardes 2007). Portanto, a eliminação da retenção, sem a devida introdução de, por exemplo, um acompanhamento mais próximo de cada aluno por parte dos professores, como advoga a maioria das propostas de ciclos, poderia gerar desestímulo nas crianças e uma consequente queda no aprendizado. Ou seja, elimina-se uma motivação extrínseca que pode ser realmente eficaz em alguns alunos sem o devido aumento na motivação intrínseca que a política de ciclos deveria, em tese, introduzir.

O segundo efeito é indireto e ocorre se os alunos que, não fosse pelo sistema de ciclos, teriam evadido, passem a influenciar os alunos que, sob o regime seriado, não iriam evadir das escolas. Esse "peer effect" pode ser negativo e relevante na medida em que um aumento na proporção de alunos desinteressados afeta o ambiente em classe e sobrecarrega o professor, afetando o desempenho de alunos e professores em sala de aula. Por outro lado, ao diminuir as distorções idade-série, a não retenção pode gerar um "peer effect" positivo, visto que há evidências de que grandes heterogeneidades na idade dos alunos em sala de aula reduz a eficiência dos métodos de ensino tradicionais (Schiefelbein \& Wolff 1993).

A combinação desses dois efeitos pode ser diferente dependendo do próprio desempenho individual do aluno. Espera-se que os efeitos da política de adoção de ciclos sejam diferenciados ao longo da distribuição de notas intraclasse, pois os alunos com notas altas, que possuem maior facilidade de aprendizado, devem ser menos diretamente afetados pela adoção de ciclos, isto é, são menos suscetíveis ao primeiro efeito, enquanto outros mais perto da linha de corte da reprovação e abaixo dela deverão ser diretamente afetados.

Embora se espere que para alunos com notas próximas a mediana possa haver uma diminuição no esforço, e que para alunos com notas melhores, o esforço não deva ser alterado, não é claro que isso se reflita diretamente em desempenho. Primeiro, a verificação de desempenho aqui adotada não está a mesma usada dentro da classe, pois são usados, neste artigo, notas de testes padronizados. Por fim, há a questão importante do efeito dos pares que pode fazer com que os melhores alunos tenham seus desempenhos afetados.

Note ainda que é esperado que a adoção de ciclos, por ter um efeito positivo esperado sobre evasão escolar, faça com que as crianças que teriam evadido sob o regime seriado, mas que permaneceram na escola no regime de ci- 
clos, efetivamente aprendam algo, isto é, tenham sua proficiência aumentada. Dessa forma, o efeito total sobre proficiência depende da população-alvo. Se a população de interesse forem todas as crianças em idade escolar, e se comparássemos proficiência apenas das crianças que frequentam escola, teríamos um viés de seleção que subestimaria o efeito da adoção do regime de ciclos sobre a população-alvo. Se a população de interesse for a população de crianças na escola, poderíamos supor que, conforme os resultados de Hanushek \& Gomes-Neto (1994) para o nordeste brasileiro de que os alunos que repetem são piores que seus pares em desempenho escolar, o sistema de ciclos deveria gerar uma piora de proficiência média, pois evitaria que crianças de pior desempenho evadissem das escolas.

Ferrão et al. (2002) usam os dados do SAEB 1999 e encontram efeitos não significativos da política de ciclos sobre o desempenho escolar nas 4as séries das escolas públicas dos estados de São Paulo e de Minas Gerais, controlando para características individuais e escolares. Mais recentemente, Menezes-Filho et al. (2005) encontraram evidências de que a adoção de ciclos diminui evasão e tem não tem impacto significativo sobre proficiência para alunos das $4^{\mathrm{a} e}$ $8^{\mathrm{a}}$ séries do ensino fundamental e da $3^{\mathrm{a}}$ série do ensino médio. Os autores, contudo, usam apenas informação do Censo Escolar e do SAEB 2001 e se atêm apenas aos efeitos médios. ${ }^{3}$

Neste trabalho fazemos a avaliação do impacto da adoção dos ciclos ao longo da distribuição intra-classe de proficiência e não apenas olhando para efeitos médios da política. Como previamente mencionado, espera-se que os efeitos da política sejam diferenciados, pois os alunos à direita da distribuição, isto é, com notas altas, podem não ser diretamente afetados pela adoção de ciclos, enquanto outros mais perto da linha de corte da reprovação e abaixo dela deverão ser diretamente afetados.

\section{Metodologia}

\subsection{Base de Dados, descrição das variáveis e a adoção das políticas de ciclos}

Neste artigo, usamos informações a respeito da infraestrutura da escola e de indicadores da qualidade do ensino, como a taxa de reprovação. Também utilizamos informações a respeito da forma de organização do ensino nas escolas contidas no Censo Escolar de 2001 e 2005. Assim, podemos localizar escolas que organizavam o ensino em séries em 2001 e que passaram a adotar os ciclos em 2005. Para tanto, obtivemos junto ao INEP informações que nos permitem identificar as escolas ao longo dos vários anos do Censo Escolar.

Utilizamos também informações dos Censos de 1991 e 2000 do Instituto Brasileiro de Geografia e Estatística (IBGE) sobre dados educacionais de cada município. ${ }^{4}$ Podemos utilizar os dados do Censo do IBGE sobre a proporção de crianças fora da escola no município ou a proporção de crianças com defasa-

\footnotetext{
${ }^{3}$ Menezes-Filho et al. (2008) refazem o exercício de Menezes-Filho et al. (2005) com dados do Censo Escolar de 2006 e da Prova Brasil de 2005. O impacto da progressão continuada permanece negativo para a taxa de evasão. $\mathrm{O}$ efeito sobre a proficiência dos alunos permanece insignificante para estudantes da $4^{\mathrm{a}}$ série, porém mostram-se negativos para alunos da $8^{\mathrm{a}}$ série, apesar de terem pouca magnitude (menos de $2 \%$ da média das notas na Prova Brasil).

${ }^{4} \mathrm{Os}$ dados do Censo do IBGE foram obtidos na página do Ipeadata, http://www.ipeadata.gov.br.
} 
gem escolar, e verificar em que medida essas características escolares dos municípios estão correlacionadas com a probabilidade de implantação dos ciclos. Obtemos ainda informação sobre a proporção dos professores que completaram o ensino superior, para averiguar se locais que dispõem de professores com melhor formação são mais propensos a organizarem o ensino em ciclos.

$\mathrm{Na}$ medida em que essas questões estão relacionadas com o desempenho escolar é fundamental saber até que ponto elas influenciam a decisão de introduzir a política de ciclos. Desse modo, dos Censos de 1991 e 2000 do IBGE obtemos:

1. Proporção de crianças entre 7 e 14 anos que não frequentam a escola no município.

2. Proporção de crianças entre 10 e 14 anos que não frequentam a escola no município por causa do trabalho. Isto é, percentual de pessoas de 10 a 14 anos de idade que trabalharam em todos ou em parte dos últimos 12 meses, e que não frequentavam a escola. Considera-se o trabalho remunerado ou não (ajuda a membros da família, aprendiz, estagiário) e também o trabalho na produção para consumo próprio.

3. Proporção de crianças com pelo menos um ano de defasagem escolar no município. O atraso escolar é obtido pela comparação entre a idade e a série escolar da criança, por meio da equação: atraso escolar $=[($ idade -7$)$ - número da série completada]. Espera-se, portanto, que uma criança de oito anos já tenha completado um ano de estudo.

4. Proporção de professores do ensino fundamental com ensino superior no município. É a razão entre o total de pessoas residentes no município que exercem a profissão de professor de curso fundamental e que têm curso superior e o total das pessoas residentes no município que exercem esta profissão.

Do Censo Escolar, além das informações sobre a organização do ensino, coletamos para cada estabelecimento dados sobre a localidade da escola, isto é, urbana ou rural, e sobre:

1. Número médio de alunos por turma no ensino fundamental.

2. Taxa de distorção idade-série no ensino fundamental. É a proporção de crianças da escola com atraso escolar.

3. Taxa de reprovação. É a proporção de alunos do ensino fundamental que não foram aprovados no ano anterior ao da realização do Censo Escolar.

4. Taxa de abandono. É a proporção de alunos do ensino fundamental que abandonaram a escola durante o ano anterior ao da realização do Censo Escolar.

5. Índices de infraestrutura da escola calculados por meio da análise de componentes principais. Os índices são: dependências da escola (salas, biblioteca, diretoria, laboratórios, quadras esportivas, ...); equipamentos da escola (impressoras, máquinas de fotocópia, televisões, retroprojetores, ...); cozinha (equipamentos da cozinha como fogão, geladeira, liquidificador, ...). Os índices foram normalizados para estarem entre 0 e 1 . 
6. Programas do governo. Índice sobre a participação da escola em programas do governo como TV-escola, distribuição de livros didáticos e transporte escolar. Também normalizado para estar entre 0 e 1 .

Na Tabela 1, apresentamos estatísticas descritivas das variáveis do Censo Escolar em 2001 para as escolas que adotam os ciclos e as que organizam o ensino em séries. Claramente percebemos que as escolas que praticavam a não retenção possuem melhor infraestrutura que as escolas seriadas, tanto em termos de um melhor espaço físico (dependências), quanto ao fato de possuírem mais equipamentos e uma melhor cozinha, apesar de, devido aos altos desvios padrões, não podermos afirmar que as diferenças sejam estatisticamente significativas, devido aos altos desvios padrão. Da mesma forma, as escolas com ciclos tendem a participar mais de programas do governo. Por outro lado, os estabelecimentos de ensino que se organizavam de forma não seriada também apresentavam em média melhores estatísticas da qualidade de ensino. Enquanto que, em 2001, 47\% dos alunos apresentavam algum atraso escolar nas escolas seriadas, a proporção nas escolas com ciclos era de $29 \%$, aproximadamente. As taxas de reprovação e abandono também são maiores nas escolas seriadas $(15,5 \%$ contra $8 \%$, e $13,3 \%$ contra $8,7 \%$, respectivamente). Apenas os tamanhos das turmas eram piores nas escolas com ciclos, 26,5 alunos por turma contra 22,3 .

Tabela 1: Estatísticas Descritivas 2001

\begin{tabular}{|c|c|c|c|c|}
\hline & \multicolumn{2}{|c|}{ Séries } & \multicolumn{2}{|c|}{ Ciclos } \\
\hline & Média & Desv-Pad & Média & Desv-Pad \\
\hline \multicolumn{5}{|c|}{ Infraestrutura } \\
\hline Dependências & 0,331 & 0,396 & 0,621 & 0,405 \\
\hline Equipamentos & 0,344 & 0,285 & 0,592 & 0,340 \\
\hline Cozinha & 0,392 & 0,384 & 0,762 & 0,327 \\
\hline Programas do Governo & 0,418 & 0,330 & 0,734 & 0,323 \\
\hline \multicolumn{5}{|c|}{ Qualidade do Ensino } \\
\hline Alunos/Turma & 22,291 & 8,969 & 26,593 & 8,521 \\
\hline Taxa Distorção Idade-série & 46,983 & 26,718 & 28,901 & 20,762 \\
\hline Taxa de Reprovação & 15,466 & 14,398 & 8,087 & 9,986 \\
\hline Taxa de Abandono & 13,305 & 15,147 & 8,728 & 11,743 \\
\hline
\end{tabular}

Fonte: Elaboração própria a partir de dados do Censo Escolar 2001, INEP.

No entanto, a maior parte das escolas com ciclos fica localizada em zonas urbanas e, como se pode notar pela comparação entre as Tabelas 1 e 2, as escolas rurais possuem uma infraestrutura e estatísticas de qualidade de ensino piores que as escolas urbanas (ver Sátyro \& Soares. 2007). Assim sendo, a Tabela 2 apresenta as estatísticas descritivas apenas para as escolas urbanas, com a finalidade de verificar o quanto as diferenças entre as escolas seriadas e com ciclos mostradas na tabela anterior são decorrentes das desigualdades entre as escolas urbanas e rurais. Nota-se facilmente que as diferenças são bem menos pronunciadas do que a tabela anterior sugere. Destaque para a redução das desigualdades nas taxas de distorção idade-série e abandono. 
Tabela 2: Estatísticas Descritivas: Apenas Escolas Urbanas 2001

\begin{tabular}{|c|c|c|c|c|}
\hline & \multicolumn{2}{|c|}{ Séries } & \multicolumn{2}{|c|}{ Ciclos } \\
\hline & Média & Desv-Pad & Média & Desv-Pad \\
\hline \multicolumn{5}{|c|}{ Infraestrutura } \\
\hline Dependências & 0,741 & 0,330 & 0,837 & 0,264 \\
\hline Equipamentos & 0,616 & 0,302 & 0,767 & 0,262 \\
\hline Cozinha & 0,727 & 0,315 & 0,903 & 0,172 \\
\hline Programas do Governo & 0,515 & 0,385 & 0,839 & 0,259 \\
\hline \multicolumn{5}{|c|}{ Qualidade do Ensino } \\
\hline Alunos/Turma & 24,901 & 9,633 & 30,509 & 6,004 \\
\hline Taxa Distorção Idade-série & 31,156 & 25,673 & 26,637 & 19,707 \\
\hline Taxa de Reprovação & 10,406 & 10,523 & 6,969 & 7,783 \\
\hline Taxa de Abandono & 9,977 & 13,273 & 8,660 & 11,526 \\
\hline
\end{tabular}

Fonte: Elaboração própria a partir de dados do Censo Escolar 2001, INEP.

Primeiramente, para tentarmos determinar o que influencia a decisão de implementar a política de ciclos, estimamos por Mínimos Quadrados Ordinários (MQO) a seguinte regressão para as redes estaduais:

$$
Y_{i}=\alpha+\beta_{1} W_{91 i}+\beta_{2} X_{i}+\beta_{3} U r b_{i}+\beta_{4} D_{-} E s t_{i}+u_{i}
$$

onde $i$ denota a escola, $Y$ é uma dummy que assume valor 1 se a escola adota a política de ciclos durante algum período do ensino fundamental no ano de $2001^{5}, W$ são características observáveis dos municípios extraídas do Censo do IBGE de 1991 (proporção de crianças fora da escola, defasagem escolar e proporção de professores com ensino superior), $X$ são índices de infraestrutura das escolas calculados a partir de dados do Censo Escolar de 2001 por meio da análise de componentes principais, ${ }^{6} \mathrm{Urb}$ é uma dummy que assume valor 1 se a escola está na região urbana e $D_{-} E s t_{i}$ são dummies para cada estado.

A racionalidade para usarmos os dados do Censo do IBGE de $1991 \mathrm{em}$ vez dos dados de 2000 é que, na medida em que a adoção dos ciclos afetará as taxas de reprovação, abandono e a distorção idade-série, precisamos obter essas informações antes da introdução da política, que teve início em meados dos anos 90. A Tabela 3 mostra os resultados para as redes estaduais.

A primeira coluna da Tabela 3 inclui apenas as variáveis do Censo de 91 . Os resultados mostram que as escolas em localidades em que, em 1991, ocorriam maiores problemas de crianças fora da escola, ou crianças fora da escola por motivo de trabalho ou maior defasagem idade-série, não apresentavam uma maior probabilidade de adotar o ensino não seriado. De fato, encontramos o contrário, os efeitos da proporção de crianças fora da escola ou da defasagem escolar são negativos, porém extremamente reduzidos (diminuem a probabilidade de adotar os ciclos em menos de $1 \%$ ), apesar de estatistica-

\footnotetext{
${ }^{5}$ Trata-se, portanto, de um modelo de probabilidade linear.

${ }^{6}$ Os índices são: dependências da escola (salas, biblioteca, diretoria, quadras esportivas,...); equipamentos da escola (impressoras, máquinas de fotocópia, televisões, retroprojetores,...); cozinha (equipamentos da cozinha) e programas do governo (se a escola participa dos vários programas educacionais do governo).
} 
mente significativos. ${ }^{7}$ Por outro lado, uma proporção maior de professores com curso superior no município afeta positivamente a probabilidade de a escola implementar os ciclos, no entanto, o efeito sobre a probabilidade é praticamente irrelevante.

Na coluna seguinte acrescentamos informações do censo escolar de 2001 sobre a infraestrutura e a localidade da escola. Notamos que praticamente não há uma correlação entre a probabilidade de adoção dos ciclos e a estrutura das dependências escolares ou a disponibilidade dos equipamentos. Percebemos também, como era esperado a partir das informações anteriores, que as escolas urbanas tendem a adotar mais os ciclos. Entretanto, quando acrescentamos as dummies para cada estado na terceira coluna, o fato de a escola ser urbana torna-se insignificante.

Talvez a informação mais relevante da Tabela 3 seja que, as variáveis concernentes à qualidade da escola e do ensino parecem não afetar a probabilidade de adoção dos ciclos, enquanto que as variáveis com maior poder preditivo sejam as dummies de cada estado como mostra a terceira coluna (note-se o R-Quadrado da terceira coluna comparado com o das duas primeiras).

Tabela 3: Determinação da adoção dos ciclos: Redes Estaduais

\begin{tabular}{|c|c|c|c|}
\hline DEP. VAR: CICLO & (1) & (2) & (3) \\
\hline Fora da Escola -91 & $\begin{array}{c}-0,00210^{* * *} \\
(0,000313)\end{array}$ & $\begin{array}{c}-0,00192^{* * * *} \\
(0,000321)\end{array}$ & $\begin{array}{c}0,00037 \\
(0,000249)\end{array}$ \\
\hline Defasagem Escolar -91 & $\begin{array}{c}-0,00759^{* * *} \\
(0,000300)\end{array}$ & $\begin{array}{c}-0,00796^{* * *} \\
(0,000318)\end{array}$ & $\begin{array}{c}-0,00315^{* * * *} \\
(0,000347)\end{array}$ \\
\hline Fora da Escola -91 -Trabalho & $\begin{array}{c}-0,00211^{* * *} \\
(0,000445)\end{array}$ & $\begin{array}{c}-0,00279^{* * *} \\
(0,000440)\end{array}$ & $\begin{array}{c}-0,00072^{* * * *} \\
(0,000232)\end{array}$ \\
\hline Professores com curso Superior-91 (EF) & $\begin{array}{c}0,00046^{*} \\
(0,000241)\end{array}$ & $\begin{array}{l}0,00080^{* * *} \\
(0,000252)\end{array}$ & $\begin{array}{c}0,00016 \\
(0,000124)\end{array}$ \\
\hline Dependências da Escola & & $\begin{array}{c}-0,00573^{* * *} \\
(0,001890)\end{array}$ & $\begin{array}{c}-0,00936^{* * *} \\
(0,001070)\end{array}$ \\
\hline Equipamentos da Escola & & $\begin{array}{c}0,00259 \\
(0,002390)\end{array}$ & $\begin{array}{c}-0,00049 \\
(0,001500)\end{array}$ \\
\hline Cozinha & & $\begin{array}{c}-0,03810^{* * *} \\
(0,002850)\end{array}$ & $\begin{array}{l}0,00624^{\text {*** }} \\
(0,001650)\end{array}$ \\
\hline Programas do Governo & & $\begin{array}{l}0,02990^{* * * *} \\
(0,001770)\end{array}$ & $\begin{array}{l}0,01180^{* * * *} \\
(0,001020)\end{array}$ \\
\hline Urbana & & $\begin{array}{l}0,05850^{* * * *} \\
(0,008790) \\
\end{array}$ & $\begin{array}{c}-0,00695 \\
(0,004580) \\
\end{array}$ \\
\hline Dummies Estados & não & não & $\operatorname{sim}$ \\
\hline Constante & $\begin{array}{l}0,776^{* * *} \\
(0,0147)\end{array}$ & $\begin{array}{l}0,728^{* * * *} \\
(0,0160)\end{array}$ & $\begin{array}{l}0,169^{* * * *} \\
(0,0175)\end{array}$ \\
\hline Observações & 33.387 & 29.108 & 29.108 \\
\hline R-Quadrado & 0,080 & 0,117 & 0,755 \\
\hline
\end{tabular}

Pode-se considerar que, por exemplo, mesmo que a defasagem escolar de um município não influencie a decisão de adotar os ciclos, a taxa de distorção idade-série da própria escola poderá afetar essa decisão, ou seja, escolas com altas taxas de distorção idade-série em um município onde a defasagem escolar seja pequena pode querer introduzir o ensino não seriado para aproximarse das estatísticas das outras escolas do município. Podemos incorporar infor-

\footnotetext{
${ }^{7}$ As conclusões seriam as mesmas se reportássemos os efeitos marginais de um probit, além disso, apenas duas observações apresentaram probabilidades previstas fora do intervalo $[0,1]$.
} 
mações sobre a qualidade do ensino da própria escola, em vez de apenas dos municípios, estimando por MQO a seguinte regressão para as redes estaduais:

$$
Y_{01 \_05 i}=\alpha+\beta_{1} W_{00 i}+\beta_{2} X_{i}+\beta_{3} U r b_{i}+\beta_{4} D \_E s t_{i}+\beta_{5} Z_{i}+u_{i}
$$

onde $Y_{01 \_05 i}$ é uma dummy que assume valores 1 se a escola adotava o ensino seriado em 2001 e passou a adotar a progressão continuada em 2005, e 0 se a escola permaneceu seriada, ${ }^{8} W$ agora se refere aos dados do Censo do IBGE de 2000, $Z$ são características da qualidade escolar obtidas no Censo Escolar de $2001,{ }^{9}$ e as demais variáveis são definidas como na equação 1.

As conclusões adotando essa abordagem são semelhantes às apresentadas na Tabela 3. Da mesma forma, as conclusões não se alteram se investigamos a adoção dos ciclos nas redes municipais. ${ }^{10}$ De modo geral, as variáveis concernentes à qualidade da escola e do ensino parecem não afetar a probabilidade de adoção dos ciclos. Apesar de ocasionalmente os coeficientes dessas variáveis se apresentarem estatisticamente significativos, seu impacto conjunto mostrou pouca relevância. Por outro lado, as dummies estaduais demonstraram um alto poder preditivo com respeito a adoção dos ciclos, sugerindo que o componente regional tenha um importante papel na probabilidade de implantar a não retenção.

\subsection{Efeitos ao longo da distribuição de desempenho}

Nesta seção, propomos uma metodologia para verificar quais os efeitos da introdução dos ciclos para diferentes percentis da distribuição da proficiência. A razão pela qual nos interessamos por efeitos distributivos da adoção de ciclos foi levantada anteriormente. Existem motivos para se acreditar que crianças no topo da distribuição de proficiência se sintam menos estimuladas sob o regime de ciclos e exerçam menos esforço. Ao mesmo tempo, a inclusão de crianças que teriam sido reprovadas sob o regime de séries pode afetar negativamente a cauda inferior da distribuição do desempenho. Assim, espera-se que possa haver efeitos diferenciados ao longo da distribuição de proficiência que seriam negligenciados pelas análises usuais que se voltam para efeitos médios.

Para se estimar o efeito ao longo da distribuição de desempenho de forma comparável ao que se obtém quando se usa estratégia de diferença em diferenças (DID), precisamos fazer alguns ajustes. Note que a estratégia de DID é preconizada para nosso problema, pois temos escolas antes e depois da adoção do regime de ciclos e esses grupos de escolas podem ser diferentes mesmo antes do início do programa de ciclos.

Diversos artigos, como Meyer et al. (1995), Poterba et al. (1995) e Athey \& Imbens (2006) discutem como proceder com estimações de modelos de DID usando regressão quantílica. O uso de regressões quantílicas é indicado neste contexto exatamente para podermos mensurar efeitos diferenciados ao longo da distribuição de desempenho acadêmico. A hipótese usualmente feita quando se usam modelos de DID em regressões quantílicas é mais forte do que

\footnotetext{
${ }^{8}$ De um total de cerca de 17.700 escolas estaduais, pouco mais de $2.000(11,5 \%)$ adotaram os ciclos entre 2001 e 2005.

${ }^{9}$ Proporção aluno por turma, taxa de distorção idade série, taxa de reprovação e taxa de abandono.

${ }^{10}$ Os resultados podem ser solicitados junto aos autores.
} 
a usual de não observáveis dos grupos de controle e tratamento seguindo trajetórias paralelas. Em regressões quantílicas com DID impõe-se que condicional a um vetor de variáveis "controle", os não observáveis tenham a mesma distribuição em qualquer grupo (controle e tratamento) e em qualquer período de tempo (antes e depois da política). Tal restrição advém de o quantil não ser um operador linear como a média, o que permite escrever diferenças de médias como médias das diferenças.

Em adição à restrição de independência entre regressores e não observáveis, impomos a restrição usual de que o quantil condicional $\tau$ (para um $\tau$ entre 0 e 1) da proficiência $Y_{i g t}$ seja linear, ou seja, assuma a forma $\alpha_{\tau}+\beta_{1, \tau} X_{i g t}+$ $\mu_{g}+\gamma_{1, \tau} G_{i g t}+\gamma_{2, \tau} T_{i g t}+\gamma_{3, \tau} D_{i g t}$, onde $G$ é uma dummy indicando que o aluno $i$ esteve em uma escola $g$ no período $t$ que adotou ciclos entre $t=0$ e $t=1$; $T$ é dummy de tempo (1 para o período pós-adoção); $D=G * T ; X$ são controles individuais; e $\mu$ um conjunto de variáveis observáveis e não observáveis no nível da escola que afetam o desempenho individual.

Nesse caso, o coeficiente $\gamma_{3, \tau}$ é o nosso parâmetro de interesse e pode ser identificado a partir de uma regressão quantílica de $Y$ em $G, T, D=G * T$ e controles. Por exemplo, para $\tau=0,5$ temos o caso da mediana:

$$
\begin{array}{r}
\gamma_{3,0.5}=\left(\operatorname{med}\left[Y_{i g t} \mid \mu_{g}, X_{i g t}, G=1, T=1\right]-\operatorname{med}\left[Y_{i g t} \mid \mu_{g}, X_{i g t}, G=1, T=0\right]\right) \\
-\left(\operatorname{med}\left[Y_{i g t} \mid \mu_{g}, X_{i g t}, G=0, T=1\right]-\operatorname{med}\left[Y_{i g t} \mid \mu_{g}, X_{i g t}, G=0, T=0\right]\right)
\end{array}
$$

No entanto, o fato de controlarmos os efeitos fixos com dummies para cada escola, torna a estimação de regressões quantílicas computacionalmente inviável. De modo a contornar essa situação estimamos o modelo com as variáveis relevantes definidas em termos de desvios individuais da média de cada escola. Isto é, consideramos a seguinte equação:

$$
Y_{i g t}-\bar{Y}_{g \bullet}=\alpha_{\tau}+\beta_{1, \tau}\left(X_{i g t}-\bar{X}_{g \bullet}\right)+\gamma_{1, \tau} G_{i g t}+\gamma_{2, \tau} T_{i g t}+\gamma_{3, \tau} D_{i g t}+\varepsilon_{i g t}
$$

onde $\bar{Y}_{g \bullet}$ é a média da proficiência da escola, e $\bar{X}_{g \bullet}$ definido de forma análoga. Note que podemos escrever problema desta forma, pois $\mu$ não varia entre quantis. Ao eliminarmos a média da escola dos valores individuais controlamos para o impacto de variáveis omitidas das escolas que influenciam a proficiência dos alunos.

A base de dados utilizada é o Sistema Nacional de Avaliação da Educação Básica (Saeb) de 2001 e a Prova Brasil de 2005, ambas realizadas a cada dois anos pelo Instituto Nacional de Estudos e Pesquisas Educacionais Anísio Texeira (Inep) do Ministério da Educação. Junto com a proficiência dos alunos, coletamos informações sobre a vida das crianças contidas nos questionários dos alunos do Saeb e da Prova Brasil. ${ }^{11}$ Utilizamos dados sobre:

\section{Características Individuais}

- Sexo: dummy que assume valor 1 se o estudante é homem.

- Idade.

\footnotetext{
${ }^{11}$ Como a Prova Brasil apenas contém o questionário dos alunos, não utilizamos os questionários do diretor e do professor disponíveis no Saeb.
} 
- Etnia: dummy que assume valores 1 se o estudante se auto-declara branco, e 0 caso contrário.

- Trabalho: dummy que assume valores 1 se o aluno trabalha fora de casa.

- Repetência: dummy que assume valores 1 se o aluno repetiu ao menos uma série.

- Abandono: dummy que assume valores 1 se o aluno já abandonou a escola anteriormente.

\section{Características domiciliares e familiares}

- Lugar de estudo: dummy que assume valores 1 se há lugar apropriado para estudos no domicílio

- Mora com pais: dummy que assume valores 1 se o aluno mora com os pais

- Nível socioeconômico (NSE): índice calculado por análise de componentes principais que busca determinar o status econômico do aluno.

- Interesse dos pais: Índice que capta o interesse dos pais dos alunos dos estudos dos filhos composto por cinco indicadores; se os pais participam das reuniões na escola, se o incentivam a estudar, ler, fazer a lição de casa e ir a escola. Normalizado para estar entre 0 e 1.

- Educação da mãe: variável que indica o grau de escolaridade da mãe; 1 se não sabe ler ou nunca estudou; 2 primário incompleto; 3 completou o primário mas não o ensino fundamental; 4 ensino fundamental completo; 5 ensino médio completo; 6 ensino superior completo

- Educação do pai: variável que indica o grau de escolaridade do pai.

Utilizamos ainda as variáveis de infraestrutura da escola obtidas dos Censos Escolares de 2001e 2005 descritas na seção anterior. ${ }^{12}$ Na Tabela 4 apresentamos estatísticas descritivas da amostra para alunos de matemática da $4^{\mathrm{a}}$ e $8^{\mathrm{a}}$ séries de 2001 e 2005, separadamente por escolas tratadas (que introduziram os ciclos entre 2001 e 2005) e do grupo de controle (que permaneceram seriadas). Pode-se notar que há poucas diferenças entre alunos das escolas com ciclos e escolas seriadas.

\section{Resultados}

Na Tabela 5 apresentamos os resultados das regressões quantílicas baseadas na equação 3 para $\tau=0,1,0,25,0,5,0,75,0,9$. São reportados apenas os coeficientes de diferenças-em-diferenças, isto é, $\gamma_{3, \tau}$, tanto para o caso da eliminação da reprovação no painel A (introdução dos ciclos), quanto para o caso do retorno ao ensino seriado no painel B (dos ciclos para as séries).

\footnotetext{
${ }^{12}$ A identificação das mesmas escolas no Saeb, Prova Brasil e Censo Escolar foi possibilitada a partir de informações obtidas junto ao Inep.
} 
Tabela 4: Estatísticas descritivas: Matemática

\begin{tabular}{|c|c|c|c|c|c|c|c|c|}
\hline & \multicolumn{4}{|c|}{ Matemática $4^{\text {a }}$ Série - 2001} & \multicolumn{4}{|c|}{ Matemática $4^{\text {a }}$ Série - 2005} \\
\hline & \multicolumn{2}{|c|}{ Controle } & \multicolumn{2}{|c|}{ Tratadas } & \multicolumn{2}{|c|}{ Controle } & \multicolumn{2}{|c|}{ Tratadas } \\
\hline & Média & Desv-Padrão & Média & Desv-Padrão & Média & Desv-Padrão & Média & Desv-Padrão \\
\hline Proficiência & 167,18 & 38,36 & 164,25 & 36,82 & 173,80 & 36,24 & 170,06 & 36,80 \\
\hline Sexo & 0,51 & 0,50 & 0,52 & 0,50 & 0,51 & 0,50 & 0,52 & 0,50 \\
\hline Idade & 10,89 & 1,71 & 10,97 & 1,60 & 10,24 & 1,70 & 10,10 & 1,72 \\
\hline Branco & 0,38 & 0,49 & 0,30 & 0,46 & 0,30 & 0,46 & 0,25 & 0,43 \\
\hline Educação Mãe & 3,31 & 1,67 & 3,31 & 1,63 & 3,67 & 1,80 & 3,69 & 1,78 \\
\hline Educação Pai & 3,61 & 1,81 & 3,69 & 1,77 & 4,01 & 1,87 & 4,06 & 1,84 \\
\hline Trabalha & 0,18 & 0,38 & 0,12 & 0,32 & 0,16 & 0,36 & 0,16 & 0,37 \\
\hline Lugar de Estudo & 0,84 & 0,36 & 0,82 & 0,38 & 0,83 & 0,38 & 0,81 & 0,40 \\
\hline Mora com Pais & 0,84 & 0,36 & 0,83 & 0,37 & 0,88 & 0,32 & 0,88 & 0,32 \\
\hline Repetente & 0,42 & 0,49 & 0,45 & 0,50 & 0,38 & 0,48 & 0,36 & 0,48 \\
\hline Abandonou & 0,19 & 0,39 & 0,19 & 0,40 & 0,12 & 0,32 & 0,13 & 0,34 \\
\hline NSE & $-0,96$ & 1,68 & $-0,96$ & 1,48 & $-0,28$ & 1,82 & $-0,20$ & 1,76 \\
\hline \multirow[t]{4}{*}{ Interesse dos pais } & 0,51 & 0,29 & 0,51 & 0,29 & 0,55 & 0,23 & 0,55 & 0,23 \\
\hline & \multicolumn{4}{|c|}{ Matemática 8a Série - 2001} & \multicolumn{4}{|c|}{ Matemática 8a Série - 2005} \\
\hline & \multicolumn{2}{|c|}{ Controle } & \multicolumn{2}{|c|}{ Tratadas } & \multicolumn{2}{|c|}{ Controle } & \multicolumn{2}{|c|}{ Tratadas } \\
\hline & Média & Desv-P & Média & Desv-P & Média & Desv-P & Média & Desv-P \\
\hline Proficiência & 230,85 & 41,59 & 227,47 & 41,46 & 234,83 & 40,84 & 233,73 & 44,01 \\
\hline Sexo & 0,46 & 0,50 & 0,47 & 0,50 & 0,46 & 0,50 & 0,47 & 0,50 \\
\hline Idade & 15,61 & 1,77 & 15,81 & 1,81 & 15,49 & 1,62 & 15,57 & 1,65 \\
\hline Branco & 0,37 & 0,48 & 0,35 & 0,48 & 0,29 & 0,45 & 0,28 & 0,45 \\
\hline Educação Mãe & 3,03 & 1,38 & 2,92 & 1,36 & 3,05 & 1,55 & 2,98 & 1,56 \\
\hline Educação Pai & 3,26 & 1,62 & 3,14 & 1,63 & 3,30 & 1,73 & 3,30 & 1,70 \\
\hline Trabalha & 0,52 & 1,00 & 0,55 & 1,04 & 0,23 & 0,42 & 0,26 & 0,44 \\
\hline Lugar de Estudo & 0,81 & 0,39 & 0,79 & 0,41 & 0,77 & 0,42 & 0,75 & 0,43 \\
\hline Mora com Pais & 0,82 & 0,38 & 0,80 & 0,40 & 0,84 & 0,37 & 0,82 & 0,38 \\
\hline Repetente & 0,52 & 0,50 & 0,53 & 0,50 & 0,44 & 0,50 & 0,43 & 0,50 \\
\hline Abandonou & 0,22 & 0,41 & 0,27 & 0,44 & 0,18 & 0,38 & 0,20 & 0,40 \\
\hline NSE & $-1,20$ & 1,72 & $-1,33$ & 1,64 & $-0,29$ & 1,88 & $-0,10$ & 1,82 \\
\hline Interesse dos pais & 0,52 & 0,29 & 0,49 & 0,29 & 0,54 & 0,22 & 0,54 & 0,23 \\
\hline
\end{tabular}

Fonte: Elaboração Própria a partir de dados do SAEB 2001 e da Prova Brasil 2005. 
Os resultados do Painel A mostram que o desempenho ao longo dos quantis analisados não tem diferenças significativas em relação à média, independentemente da prova ou da série. Nenhum dos coeficientes foi estatisticamente significantivo, indicando que a introdução das políticas de ciclos não teve efeito algum ao longo da distribuição do desempenho acadêmico, nem sobre os alunos com pior desempenho como talvez se pudesse esperar.

Por sua vez, as informações contidas no Painel B indicam que é possível que o retorno ao ensino seriado possa ter tido efeitos variados sobre alunos com diferentes desempenhos. A reintrodução da ameaça da reprovação teve um efeito positivo sobre o desempenho acadêmico dos alunos da $4^{\text {a }}$ série em matemática. Porém, para a $8^{\mathrm{a}}$ série e em português, não há evidências de efeitos substanciais. Por exemplo, na prova da língua portuguesa na $4^{\mathrm{a}}$ série, onde ocorreu a maior variação ao longo da distribuição, a diferença do desempenho em relação à média entre o $10^{\circ}$ e o $90^{\circ}$ percentil, foi de apenas 5 pontos aproximadamente.

Os distintos resultados entre a $4^{\mathrm{a}} \mathrm{e}$ a $8^{\mathrm{a}}$ série podem ser causados pelas diferenças de maturidade entre os alunos. Alunos que estão no final do ensino fundamental talvez sejam menos suscetíveis às motivações extrínsecas como a reprovação, pois já podem ter uma visão mais clara do que se pode obter por meio da educação e possuem melhor conhecimento de suas capacidades. De certa forma, os resultados para língua portuguesa corroboram essa interpretação, pois, apesar de serem estatisticamente iguais a zero, os coeficientes para a $8^{\mathrm{a}}$ série são menores que para os alunos da $4^{\mathrm{a}}$ série, o que sugere que, de fato, os estudantes da $4^{\mathrm{a}}$ série seriam mais propensos a melhorarem seu desempenho com a reintrodução da reprovação.

Tabela 5: Regressão Quantílica - Desvios da média

\begin{tabular}{|c|c|c|c|c|c|c|}
\hline \multirow{2}{*}{$\begin{array}{l}\text { Painel A } \\
\text { Série->Ciclos }\end{array}$} & \multicolumn{6}{|c|}{ Percentil } \\
\hline & 10 & 25 & 50 & 75 & 90 & $\mathrm{~N}^{\circ} \mathrm{Obs}$ \\
\hline Matemática $4^{\mathrm{a}}$ Série & $\begin{array}{c}-0,279 \\
(2,315)\end{array}$ & $\begin{array}{c}0,549 \\
(1,589)\end{array}$ & $\begin{array}{c}2,810 \\
(1,780)\end{array}$ & $\begin{array}{c}2,036 \\
(2,090)\end{array}$ & $\begin{array}{c}2,774 \\
(2,583)\end{array}$ & 54.042 \\
\hline Português $4^{\mathrm{a}}$ Série & $\begin{array}{r}2,917 \\
(2,055)\end{array}$ & $\begin{array}{r}1,182 \\
(1,740)\end{array}$ & $\begin{array}{r}-1,252 \\
(1,751)\end{array}$ & $\begin{array}{r}-0,757 \\
(2,008)\end{array}$ & $\begin{array}{r}-0,156 \\
(2,693)\end{array}$ & 54.909 \\
\hline Matemática $8^{a}$ Série & $\begin{array}{r}-1,533 \\
(2,662)\end{array}$ & $\begin{array}{r}-1,175 \\
(2,220)\end{array}$ & $\begin{array}{c}0,233 \\
(1,997)\end{array}$ & $\begin{array}{c}1,641 \\
(2,201)\end{array}$ & $\begin{array}{c}3,644 \\
(2,638)\end{array}$ & 66.046 \\
\hline Português $8^{\text {a }}$ Série & $\begin{array}{r}-0,127 \\
(2,645)\end{array}$ & $\begin{array}{c}2,014 \\
(1,982)\end{array}$ & $\begin{array}{c}-0,510 \\
(2,088)\end{array}$ & $\begin{array}{c}3,005 \\
(2,305)\end{array}$ & $\begin{array}{c}4,109 \\
(2,977)\end{array}$ & 66.336 \\
\hline Painel B & \multicolumn{6}{|c|}{ Percentil } \\
\hline (Ciclos->Série) & 10 & 25 & 50 & 75 & 90 & $\mathrm{~N}^{\circ} \mathrm{Obs}$ \\
\hline Matemática $4^{\mathrm{a}}$ Série & $\begin{array}{l}7,850^{* * *} \\
(2,977)\end{array}$ & $\begin{array}{l}5,770^{* * *} \\
(1,991)\end{array}$ & $\begin{array}{l}5,632^{* * *} \\
(2,075)\end{array}$ & $\begin{array}{l}5,081^{* *} \\
(2,006)\end{array}$ & $\begin{array}{l}5,877^{* *} \\
(2,514)\end{array}$ & 29.031 \\
\hline Português $4^{\mathrm{a}}$ Série & $\begin{array}{c}0,716 \\
(2,231)\end{array}$ & $\begin{array}{c}2,119 \\
(1,975)\end{array}$ & $\begin{array}{c}1,977 \\
(1,828)\end{array}$ & $\begin{array}{c}3,260 \\
(1,984)\end{array}$ & $\begin{array}{l}5,078^{*} \\
(2,701)\end{array}$ & 29.550 \\
\hline Matemática $8^{a}$ Série & $\begin{array}{c}2,890 \\
(2,585)\end{array}$ & $\begin{array}{c}2,680 \\
(1,809)\end{array}$ & $\begin{array}{l}3,820^{* *} \\
(1,858)\end{array}$ & $\begin{array}{c}2,429 \\
(1,989)\end{array}$ & $\begin{array}{c}1,996 \\
(2,384)\end{array}$ & 26.654 \\
\hline Português $8^{a}$ Série & $\begin{array}{c}0,716 \\
(2,211)\end{array}$ & $\begin{array}{c}1,629 \\
(1,846)\end{array}$ & $\begin{array}{r}1,327 \\
(1,699)\end{array}$ & $\begin{array}{c}-1,226 \\
(1,824)\end{array}$ & $\begin{array}{c}0,795 \\
(2,455)\end{array}$ & 26.391 \\
\hline
\end{tabular}

Fonte: Elaboração própria.

Desvio Padrão entre parênteses. ${ }^{* *} p<0,01$; ${ }^{* *} p<0,05 ;{ }^{*} p<0,1$. 


\section{Conclusões}

Os principais resultados encontrados neste artigo agora apontam no sentido de terem sido muito pouco significativos os efeitos da adoção de ciclos sobre desempenho dos alunos ao longo dos quantis da distribuição de desempenho. Pode-se concluir que, em geral, a reprovação não parece ser um mecanismo forte para gerar aumentos de esforço dos alunos, sobretudo entre alunos mais velhos. Acreditamos que haja pelo menos dois motivos que possam explicar esses resultados: um é a baixa qualidade da escola pública brasileira, outro é a falta de perspectivas que os alunos dessas escolas enfrentam.

Como dissemos, uma motivação extrínseca, se for somente punitiva como a retenção, não será suficiente se não for acompanhada de alguma motivação intrínseca. Um ensino público de péssima qualidade enfrentará dificuldades em conseguir estabelecer nos alunos uma valorização da educação e do conhecimento. Agrega-se a essa dificuldade o fato de que os alunos que frequentam a escola pública são aqueles cujo ambiente domiciliar não é propício a essa valorização na maioria dos casos. Dessa forma, a ameaça da repetência pode ser pouco eficaz em induzir a maior parte dos estudantes a se aplicarem mais. Do mesmo modo, se os alunos das escolas públicas não vislumbram a educação como mecanismo de ascensão social, de modo que haja praticamente nenhuma motivação intrínseca, dificilmente a ameaça de reprovação servirá de estímulo aos estudos. Ou seja, se pela falta de modelos intelectuais adequados ou pela a baixa qualidade do ensino público, os alunos não aspirarem ou perceberem que não terão condições de ingresso no ensino superior, a ausência de motivação pode tornar a ameaça da retenção inócua.

Entretanto, entre escolas que adotaram o sistema de ciclos no passado, mas que retornaram ao regime seriado, a adoção das séries gerou impactos positivos no desempenho de matemática na 4 a série para todos os pontos da distribuição de desempenho. Atribuímos, como discutimos acima, a diferença dos resultados entre a $4^{\mathrm{a}} \mathrm{e}$ a $8^{\mathrm{a}}$ série às diferenças de maturidade entre os alunos, ou seja, acreditamos que nas escolas públicas brasileiras alunos mais velhos sejam mais desmotivados e, portanto, menos suscetíveis a se influenciarem pela ameaça da reprovação.

Cabe notar, que Roderick et al. (2002) e Allensworth (2005) mostram que a introdução dos testes de alto risco, aumentando a ameaça de retenção, parece ter melhorado o desempenho dos alunos de Chicago. No entanto, os autores notam que os resultados positivos da retenção sobre os alunos retidos tendem a desaparecer em alguns anos. Uma possível ampliação dessa pesquisa seria considerar se é possível que os efeitos positivos da ameaça da retenção sejam sustentáveis no longo prazo.

\section{Referências Bibliográficas}

Allensworth, E. (2005), 'Dropout rates after high stakes testing in elementary school: a study of the contradictory effects of chicagos efforts to end social promotion', Educational Evaluation and Policy Analysis 27(4), 341-364.

Athey, S. \& Imbens, G. (2006), 'Identification and inference in nonlinear difference-in-differences models', Econometrica 74(2), 431-497. 
Ferrão, M., Beltrão, K. \& Santos, D. (2002), 'O impacto de políticas de nãorepetência sobre o aprendizado dos alunos da $4^{\circ}$ série', Pesquisa e Planejamento Econômico 32(3), 495-514.

Filmer, D. \& Pritchett, L. (1999), 'The effect of household wealth on educational attainment: Evidence from 35 countries', Population and Development Review 25(1), 85-120.

Franco, C. (2004), 'Ciclos e letramento na fase inicial do ensino fundamental', Revista Brasileira de Educação 25(1), 30-38.

Hanushek, E. \& Gomes-Neto, J. (1994), 'Causes and consequences of grade repetition: Evidence from brazil', Economic Development and Cultural Change 43(1), 117-148.

Jacob, B. \& Lefgren, L. (2009), 'The effect of grade retention on high school completion', American Economic Journal: Applied Economics 1(3), 33-58.

Jimerson, S., Anderson, G. \& Whipple, A. (2002), 'Winning the battle and losing the war: Examining the relation between grade retention and dropping out of high school', Psychology in the Schools 39(4), 441-457.

King, E., Orazem, P. \& Paterno, E. (2008), Promotion with and without learning: Effects on student enrollment and dropout behavior, Working Paper 08025, ISU Economics.

Mainardes, J. (2007), Reinterpretando os Ciclos de Aprendizagem, $1^{\text {a }}$ edição edn, Cortez, São Paulo.

Manacorda, M. (2012), 'The cost of grade retention', The Review of Economics and Statistics 94(2), 596-606.

Menezes-Filho, N., Vasconcellos, L. \& Werlang, S. (2005), Avaliando o impacto da progressão continuada no brasil, in 'XXVII Encontro Brasileiro de Econometria, Natal, Rio Grande do Norte'. Trabalho apresentado na reunião anual da Sociedade Brasileira de Econometria.

Menezes-Filho, N., Vasconcellos, L., Werlang, W. \& Biondi, R. (2008), Evaluating the impact of the progressão continuada program o student flow rates and performance in brazil, in 'XIII Latin American and Caribbean Economic Association (LACEA) Annual Meeting'. Trabalho apresentado na reunião anual da Latin American and Caribbean Economic Association, 2008.

Meyer, B., Viscusi, W. \& Durbin, D. (1995), 'Workers' compensation and injury duration: Evidence from a natural experiment', American Economic Review 85(3), 322-340.

Poterba, J., Venti, S. \& Wise, D. (1995), 'Do 401(k) contributions crowd out other personal saving?', Journal of Public Economics 58(1), 1-32.

Ribeiro, S. (1991), 'A pedagogia da repetência', Estudos Avançados 5(1), 7-21.

Roderick, M. \& Engel, M. (2001), 'The grasshopper and the ant: motivational responses of low-achievement students to high-stakes testing', Educational Evaluation and Policy Analysis 23(3), 197-227. 
Roderick, M., Jacob, B. \& Bryk, A. (2002), 'The impact of high-stakes testing in chicago on student achievement in promotional gate grades', Educational Evaluation and Policy Analysis 24(4), 333-357.

Schiefelbein, E. \& Wolff, L. (1993), 'Repetition and inadequate achievement in latin america's primary schools: a review of magnitudes, causes, relationships and strategies', Estudos em Avaliação Educacional 7(1), 45-88.

Sátyro, N. \& Soares. (2007), Anatomia das escolas brasileiras: um estudo sobre a infra-estrutura das escolas de ensino fundamental com base no censo escolar de 1997 a 2005, Texto para Discussão 1267, Ipea.

Wolff, L., Schiefelbein, E. \& Schiefelbein, P. (2002), Primary education in latin america: the unfinished agenda, Technical Papers Series EDU-120, Sustainable Development Department, Inter-American Development Bank, Washington. 